
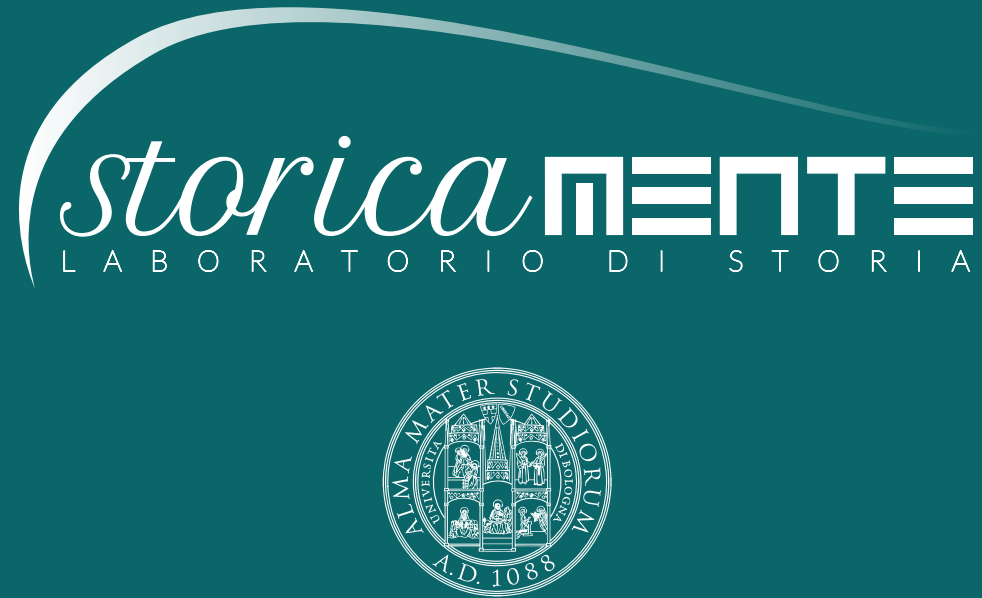

ALMA MATER STUDIORUM

Università di Bologna

Dipartimento di Storia Culture Civiltà

BIBLIO

TECA 


\section{STORICAMENTE.ORG}

\section{Laboratorio di Storia}

\section{Maria Pia Casalena}

Christophe Charle, "La dérégulation culturelle. Essai d'histoire des cultures en Europe au XIXe siècle”

Numero 11 - 2015

ISSN: $1825-411 \mathrm{X}$

Art. 28

pp. 1-3

DOI: $10.12977 /$ stor614

Editore: BraDypUS

Data di pubblicazione: 24/02/2016

Sezione: Biblioteca 


\title{
Christophe Charle, "La dérégulation culturelle. Essai d'histoire des cultures en Europe au XIXe siècle"
}

\author{
MARIA PIA CASALENA
}

Christophe Charle, "La dérégulation culturelle. Essai d'histoire des cultures en Europe au XIXe siècle", Paris: Presses Universitaires de France, 2015, $745 \mathrm{pp}$.

Charle ha pubblicato questo ponderoso volume che prende le mosse dai Lumi del Settecento e si arresta al 1914 per celebrare da una visuale inconsueta il centenario della prima guerra mondiale. Esito di ricerche pluridecennali sulla cultura francese ed europea, sugli intellettuali del XIX secolo, sulla società dei giornali e dello spettacolo, il saggio propone in effetti la ricostruzione di un processo di liberazione ed emancipazione culturale su scala continentale che si sarebbe traumaticamente interrotto con il conflitto e sarebbe poi stato parzialmente smentito dal ritorno del controllo statale sulla produzione dei «beni simbolici». L'autore parte da una tesi di fondo: con la Rivoluzione francese l'Europa dichiarò guerra all'antico regime culturale, alimentato di gerarchie, censure, strapotere ecclesiastico, dispotismi, insanabili sperequazioni sociali. Si avviò da lì un processo, beninteso molto diversificato e per lunghi tratti accidentato, di allargamento del pubblico, di contamina- 
zioni transnazionali, di superamento delle barriere di classe e nazionali che, pur non conducendo assolutamente ad una democrazia "perfetta", all'alba del XX secolo esibiva pertanto i tratti di uno scambio proficuo tra ceti alti e ceti popolari, tra nazioni «dominanti» e nazioni periferiche, fino all'affermazione delle prime forme letterarie e di spettacolo propriamente universali.

Basato come detto su ricerche precedenti e su una aggiornata letteratura francese, tedesca e britannica (in misura minore italiana e spagnola), questo saggio propone un'idea estremamente comprensiva di cultura: si passa dalla letteratura al giornalismo, dalla musica alla pittura, dal teatro alla danza. Particolarmente significative, a nostro avviso, le pagine in cui Charle discute la tesi di un irrigidimento delle barriere culturali nazionali tra 1870 e 1910: un uso più corretto delle statistiche sul consumo di opere in lingua straniera e di traduzioni lo conduce a ridimensionare di molto la portata, che pure non nega assolutamente, del nazionalismo culturale. Altrettanto interessanti i paragrafi sulle avanguardie e le varie «secessioni» artistiche, delle quali si considera peraltro tiepidamente la capacità di rottura radicale con la tradizione e soprattutto l'effettiva penetrazione nei consumi e nei gusti delle classi subalterne.

Molto altro si trova in questo libro: la fortuna del romanzo storico, la diffusione e l'adattamento del melodramma alle varie aspettative nazionali, la nascita della categoria di "patrimonio» e la conseguente musealizzazione che investì l'Europa urbana nel corso dell'Ottocento, i frequenti "paradossi dell'arretratezza» che portarono in prima fila i paesi dell'Est, tutte le «rivoluzioni simboliche» della seconda metà del secolo, infine una trattazione originale della fortuna del genere poliziesco. Charle fa tesoro, sempre rileggendole attraverso le lenti della sociologia di Pierre Bourdieu, di opere storiografiche apparse a partire dagli anni Sessanta del Novecento, con una particolare sensibilità per la storiografia culturale francese dell'ultimo decennio. Abbondante anche il ricorso a statistiche di prima o seconda mano, come dimostrano le tante tabelle che arricchiscono la narrazione. Affiora pure, soprattutto nella secon- 
da parte - dedicata alle tante vie della «modernizzazione culturale» nel continente - un approccio di genere che dà conto del minor accesso femminile ai beni simbolici prima dell'esplosione della letteratura "rosa" nel ventennio tra le due guerre.

La ricostruzione proposta da Christophe Charle, che nell'epilogo si sofferma sulle peculiarità della prima dérégulation culturelle in confronto all'americanizzazione novecentesca, può prestarsi a molte e diverse interpretazioni. Di sicuro essa stimola l'approfondimento della ricerca su questioni solo apparentemente risolte della storia culturale del XIX secolo sia per quanto concerne i singoli paesi che per quanto concerne la comparazione su scala continentale. Né storia nazionale né storia globale, la storia d'Europa di Charle si propone nel 2015 come riflessione su un momento fondamentale e non più recuperato dell'integrazione culturale europea, il quale, con tutti i suoi limiti di classe, di censo, di genere, potrebbe essere addirittura proposto come viatico per la politica continentale del XXI secolo. 